\title{
AC 2010-488: STUDENT BALLOONING PROJECT: AN EFFORT TO CREATE SUSTAINABLE UNDERGRADUATE RESEARCH EXPERIENCE IN A MINORITY INSTITUTION
}

\section{Atin Sinha, Albany State University}

Atin Sinha is the Professor and Coordinator of the Engineering Program at Albany State University. He received his Ph.D. in Aerospace Engineering from the University of Tennessee Space Institute in 1984. He had worked in Learjet and Honeywell before moving to academia in 1990. He is also a Registered Professional Engineer. Currently, he is engaged in motivating undergraduate students in inquiry based learning through hands-on, realistic projects. 


\title{
Student Ballooning Project: An Effort to Create Sustainable Undergraduate Research Experience in a Minority Institution
}

\begin{abstract}
High altitude ballooning project has gradually become an accepted method of initiating undergraduate students in scientific research through an exciting "out of the world" perspective. Traditionally student ballooning projects throughout the country have been led either by military academies or major research universities. Only recently, through an NSF sponsored effort, some of the minority universities are getting initiated into the student ballooning project that starts with a summer training program of faculty/student teams and continues throughout the following academic year with an expanded student body to design and launch a new payload. The summer experience for the team from Albany State University and subsequent student activities towards payload design with an aim to launch in next summer is described here. Successful launch and retrieval of the scientific data is hoped to inspire the next batch of students to continue the ballooning project as a sustainable research program.
\end{abstract}

\section{Introduction}

High altitude ballooning project by undergraduate students have been attempted by a number of universities in the past. In general these projects have proved that undergraduate students are capable of working on a complex scientific problem on their own with moderate supervision if they can be motivated to be part of an exciting project. Apart from the obvious scientific merit of such projects, one significant outcome is the research experience gained by the students in crossdisciplinary and team oriented problem solving practice that is so valuable in today's highly competitive global market.

To date only a handful of universities have been able to sustain the student ballooning activity on an ongoing basis. Minority institutions have only recently started developing their own ballooning projects either in conjunction with such an existing activity or as a standalone effort. Albany State University (ASU), a historically black university, located in the south, is one such institution that has just started to develop a student ballooning project as a mechanism to establish sustainable research experience for the science and engineering students.

\section{Historical Background}

Student ballooning project is going on in different parts of USA since the mid 1990. Liefer ${ }^{1}$ of U.S. Air Force academy described the early history of student balloon payload projects in U.S. with particular reference to the first student built "balloon satellite" launch in spring of 1995. Wick $^{2}$ et.al. of U.S. Naval Academy reported a junior level project of a balloon-borne environmental sensing mission in a sensor course in systems engineering major. The systems engineering approach was introduced in the classroom at University of North Dakota by Won 3 et.al. through the design, document, build and launch of Scorpio Alpha and Scorpio II between 2000 and 2001. Ellison 4 et.al. of Louisiana State University described the BalloonSat program for launching multiple student built small payloads carrying different science experiments. More 
recently in December 2008, freshmen students of MAE department of UC San Diego under the sponsorship of California Space Grant launched payloads up to $84000 \mathrm{ft}$. as an Aerospace

Engineering class project 5 .

\section{Student Ballooning Project at Louisiana State University}

In early 2000, as part of National Space Grant Student Satellite Program, the Aerospace Catalyst Experiences for Students (ACES) was developed in Louisiana State University (LSU) to provide students with cross disciplinary training in science and engineering and practical skills such as teamwork, communications, documentation and project management by means of designing and conducting science experiments in near space environment. With an initial debut in 2002-03 academic year, first launch under the ACES program occurred in May '03. Since then student built payload of increasing complexity was launched every year in a high altitude balloon. In 2007, under the sponsorship of National Science Foundation, LSU launched the Physics and Aerospace Catalyst Experiences in Research (PACER) program to attract and retain students in STEM fields in minority institutions, provide them with a research experience that builds skills, techniques and methodologies applicable throughout their science career and establish a core of expertise in minority institutions around which a local sustainable student research experience can develop.

PACER program is implemented by training one or two faculty/student teams from minority serving institutions each year during 9 weeks of summer by providing them skills in electronics, real time programming, design and management which they apply to design, fabricate and operate a small $(\sim 500 \mathrm{gm})$ science experimental payload carried to the edge of space in a helium filled balloon. During the following academic year, the teams return to the respective campuses, organize new student groups and replicate the activities of the previous summer with a new science experiment thereby establishing a student research culture and infrastructure which is hoped to be self-sustaining. PACER support is provided to the institutions for the first three years in the form of mentoring, site visits, limited financial aids and electronic components to fabricate the payloads.

From the beginning, PACER was conceived so that students have to think through each step of their research project, come up with a solution strategy and test it under the guidance of the project advisors. Besides the initial introduction to the electronics and programming, a rigorous training in project management, cost control and documentation as required in any real life science and engineering projects is taught in the Student Ballooning Course during the first 3 weeks of the summer training.

\section{Engineering Program at Albany State University}

Albany State University conducts the Regents Engineering Transfer Program (2+2) and Dual Degree Program $(3+2)$ to transfer students to Georgia Institute of Technology (Georgia Tech), the flagship research university of the state, under a cooperative agreement. In order to matriculate, engineering students have to complete core course requirements in humanities, social sciences, sciences and mathematics as well as several engineering courses required in their respective major areas such as Engineering Graphics, Mechanics, Material Sciences, Electric 
Circuits etc. Besides, all engineering students are required to take an introductory engineering course called "Principles of Engineering Analysis and Design" in the sophomore year. A laboratory component was introduced to this course in the academic year 2002-03 to create excitement about the engineering subjects among the students as well as expose them to modern manufacturing and testing equipment. The laboratory projects are based on an array of hardware and software such as Lego-Nxt programmable robots, PC Turn 55 CNC machine, FLOTEK wind tunnel, Dimension 3D printer, NextEngine 3D scanner, SolidWorks CAD and RapidWorks reverse engineering software. As is evident from the list of the equipment, an attempt was made to expose students to realistic and engaging learning experience by making them perform a wide variety of experiments and in so doing challenge themselves to engage in critical thinking in the underlying hypothesis of those experiments. However, student engagement in the course material particularly in the 2000 level courses remained a continuing problem which resulted in large failure rate resulting in increased change of major out of engineering. As such when PACER program solicitation was announced, we decided that it will be a wonderful opportunity to reinvigorate the entire student body with hands-on interdisciplinary problem solving technique in an exciting manner and increase their curiosity which will make them more engaged in studies. It was fortunate that the teams from ASU along with Central State University (CSU) from Ohio were selected by the PACER program authorities for undergoing training in the summer of 2009.

\section{PACER Summer Program Experience}

\section{Student Ballooning Course}

The course is comparable to any normal 3 credit hour course with an additional hour for hands-on laboratory projects. Indeed LSU offers "Student Ballooning Course" (SBC) every fall semester as a graded course and also to participants of the PACER program during the summer to train them in designing and operating the payload. As there is a wide variety of topics covered, team teaching method has been adopted with at least 3 to 4 experts covering materials from their individual specialty. A large multipurpose room with plenty of available table space to complete the hands-on activities as well as develop the flight payload is the right choice to conduct this course.

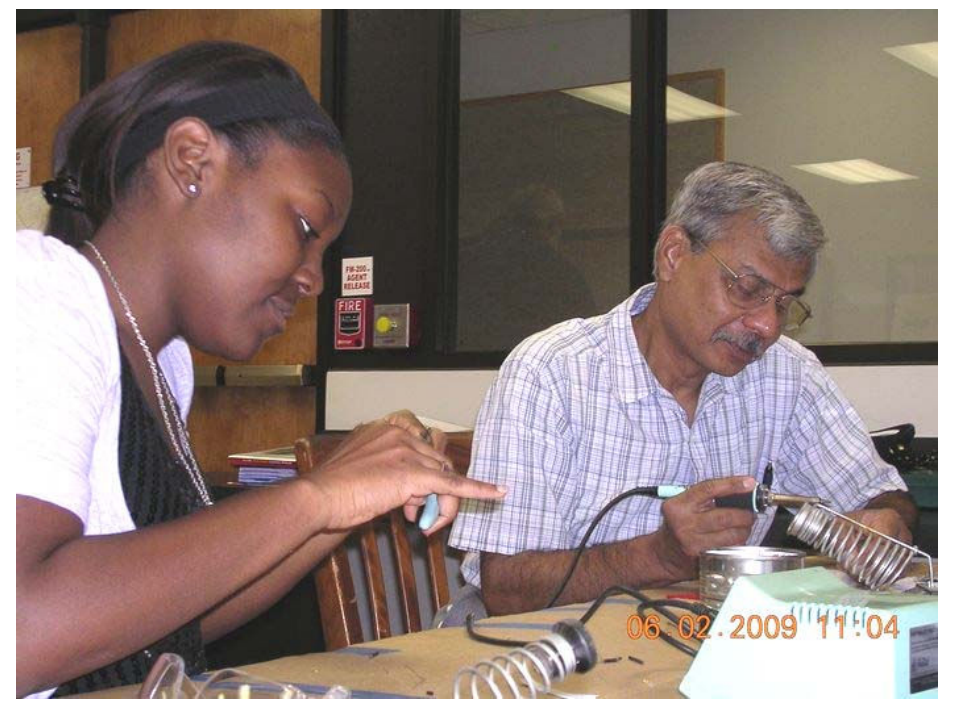

Figure 1. First lesson on soldering during Student Ballooning Course 
The students are first provided an overview of the previous balloon launch and recovery for various science experiments, introduced to electronic components, circuit drawing and prototyping, different sensors for measuring atmospheric parameters, data acquisition and data logging, analog to digital converter, real time clock etc. Then the students are made familiar with the BASIC Stamp microprocessor that is used to control other components and its peripherals such as EEPROM to store the collected data. A substantial amount of time is spent in teaching the real time programming using BASIC Stamp with the help of flowchart developed from the problem statement. Mechanical design, thermal concerns, hardware fabrication and testing, systems integration and testing are covered next. Lectures on project management, cost control, risk tolerance and contingency planning are also included as teams are supposed to meet various deadlines and cost and weight budget. Students are also provided information on balloon tracking software and have to attend weekly classes on ham radio operation to facilitate recovery of the payload. By the end of the summer program it is expected that a majority of the students will obtain at least their technician class ham radio operator's licensing. Lectures are supplemented by hands-on activities such as soldering the electronics components and real time programming to control LEDs by external input such as light or temperature. Students make Skeetersat prototype and BalloonSat, the electronic platform consisting of BASIC Stamp microprocessor, analog to digital converter, real time clock and EEPROM that will be used later in building the payload with its array of sensors customized for the specific science experiment.

\section{Payload Design, Fabrication and Testing}

After the end of the SBC, for the next 5 weeks, the payload design, fabrication and testing took place. Students are required to start their payload design starting from the objectives outlined in the science experiment they want to perform. For the beginners it most likely will be measuring some basic parameters such as temperature and pressure as a function of the altitude though in the past, student teams had developed experiments to measure ozone and ultraviolet radiation as well as cosmic ray intensity. In 2009, both PACER teams decided to measure the temperature and pressure and collect images with digital cameras. ASU team had two temperature sensors, one to measure the surface temperature of the payload and the other to measure true ambient temperature, where as CSU team used only one temperature sensor on the surface. Both teams had pressure sensors to record pressure as a function of altitude while ASU team used video camera, CSU had still pictures taken at fixed intervals.

During the process of payload design and fabrication, numerous decisions had to be made after researching the available data in the manufacturers' website or open literature and applying deductive reasoning to satisfy the science and technical requirements obtained from the mission goal and objectives. These included but were not limited to the selection of sensor type, range of operation and sampling rate, calibration, signal conditioning, sensor interfacing and schematic diagram, power requirement, software design for data acquisition and retrieval, mechanical design and fabrication method, integration of all subsystems and testing at various stages. 


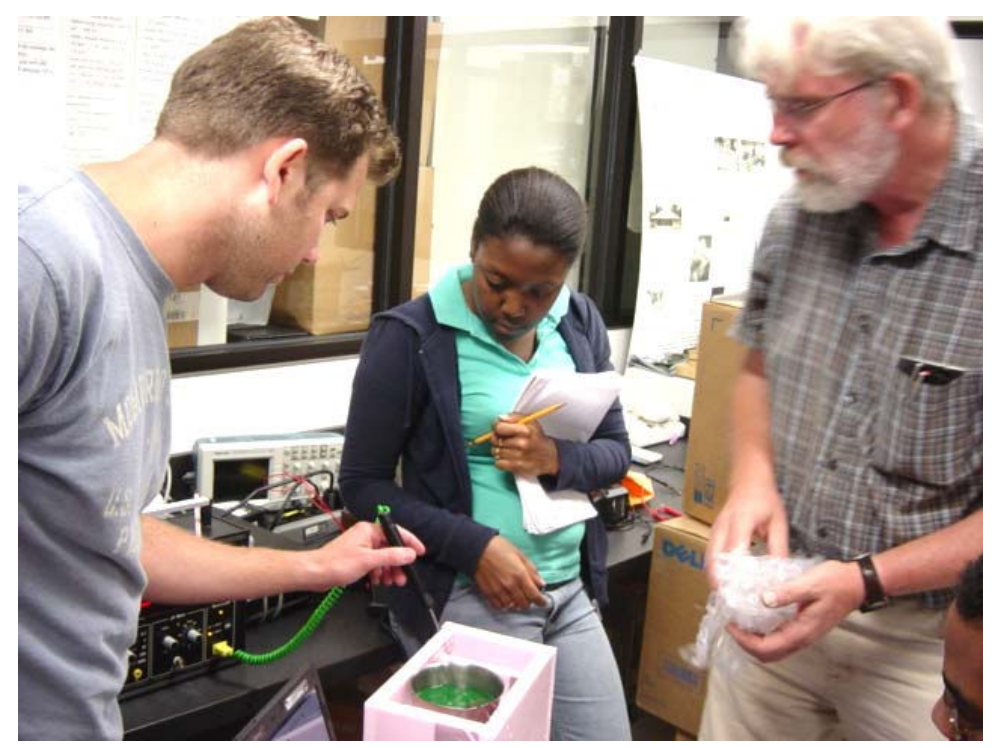

Figure 2. Low temperature testing with dry ice and antifreeze

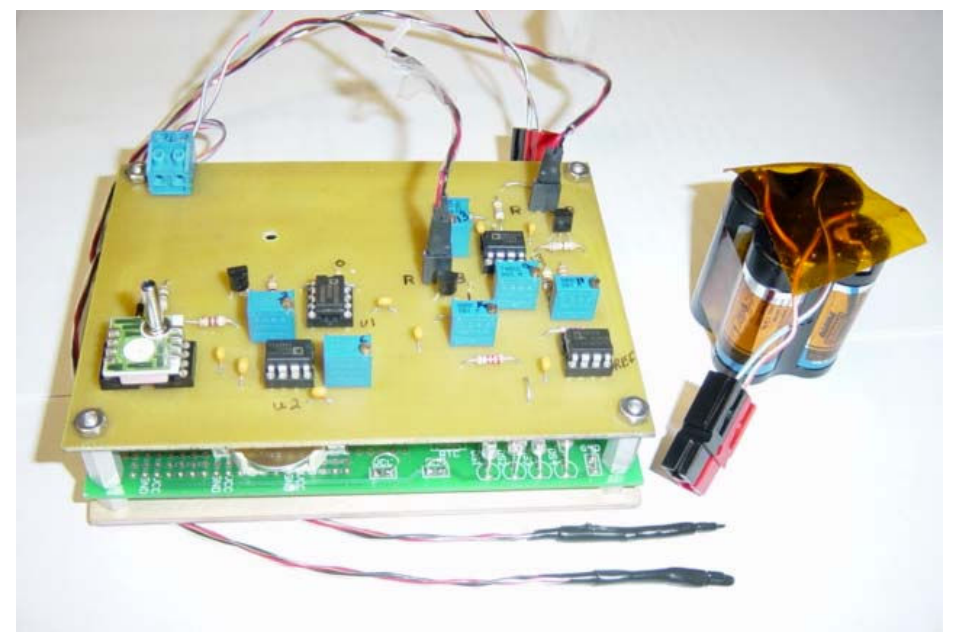

Figure 3. Assembled payload (BalloonSAT and sensors) with battery pack
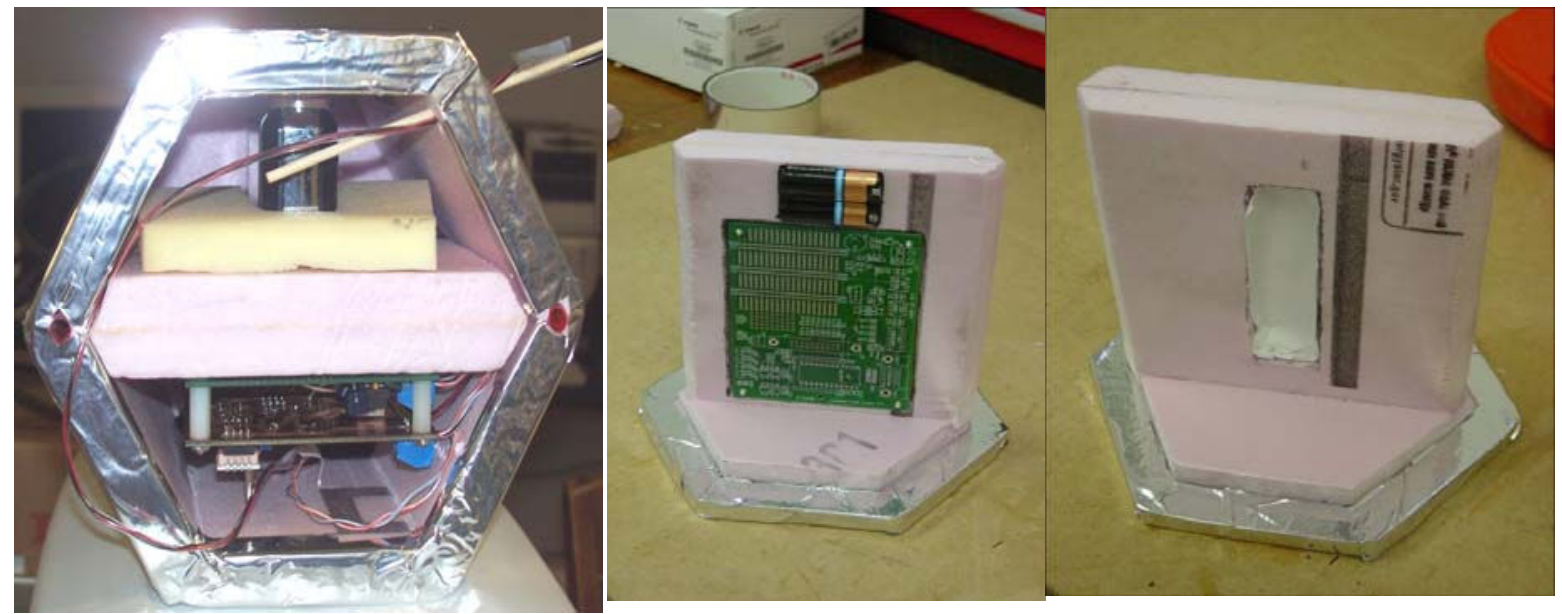

Figure 4. Payload Details (Internal Structure on left and support for BalloonSat, battery pack and camera on right) 


\section{Project Management and Documentation}

It is important to mention that the PACER program adopted the systems engineering approach which means that the design and documentation must be completed before any fabrication can be done. Specific emphasis was given on project management such as to meet various deadlines and specifically weight restriction as this turns out to be the most critical operational constraint. Gantt chart was used to keep track of project activities and had to be updated at regular intervals to take care of any delay in completion of tasks due to human failure or non availability of supplies. The teams had to develop and defend a Preliminary Design Review (PDR) of their payload concept which was followed by a Critical Design Review (CDR) several weeks later before the PACER program staff members. Both of these reviews required written documents specifying all aspects of payload design as it is progressing and an oral presentation highlighting the important aspects. The input provided by the reviewers had to be addressed before the next go around. Actual fabrication could not start till the CDR was presented and approved. Once the payload design and fabrication was finished, a final document called Flight Readiness Review (FRR) had to be completed to assess whether each payload could be operated safely without any harm to the others.

\section{Launch, Recovery and Science Presentation}

During the last week of the 9 week long summer program, the teams traveled to Palestine, Texas to launch their payloads from NASA's Columbia Scientific Balloon Facility. In all there were 9 payloads, most of them developed by the student teams either from current or previous PACER programs or from LSU students. Each payload was restricted to $500 \mathrm{~g}$ though a few did exceed that limit by a small amount. The day before the launch was spent in the final preparation of getting the equipment and software flight ready. The weather forecast predicted morning showers. But decision was taken to attempt the launch anyhow and as such everyone assembled at the field by 6 o'clock in the morning. As predicted heavy shower delayed the launch. After the rain stopped, first attempt to launch had to be aborted because

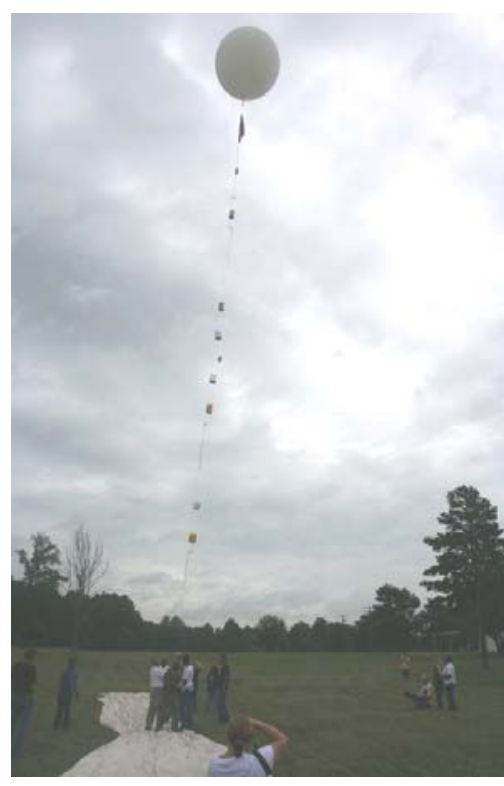

Figure 5.

Launch under a cloudy sky of a leak in the balloon which resulted in significant loss of lift. Around 10 am under a cloudy sky the second balloon was launched with its array of payload boxes hanging down from the strings. Next began the chase in multiple vehicles as the balloon climbed about $85000 \mathrm{ft}$ when the payloads unexpectedly got separated from the balloon and started descending under the parachute and ultimately landed about $60 \mathrm{ft}$ up on top of large group of trees. Repair crew working nearby in a vehicle with high rising cab helped untangle the payload boxes and safely got them to the ground.

Next day the teams went back to the NASA facility to retrieve the scientific data from the payloads and worked on the data analysis and preparation for the presentation on the following day. The balloon ascent and descent time was shown as a function of altitude in Figure 7. ASU team obtained very exciting result that showed a marked difference in ambient 

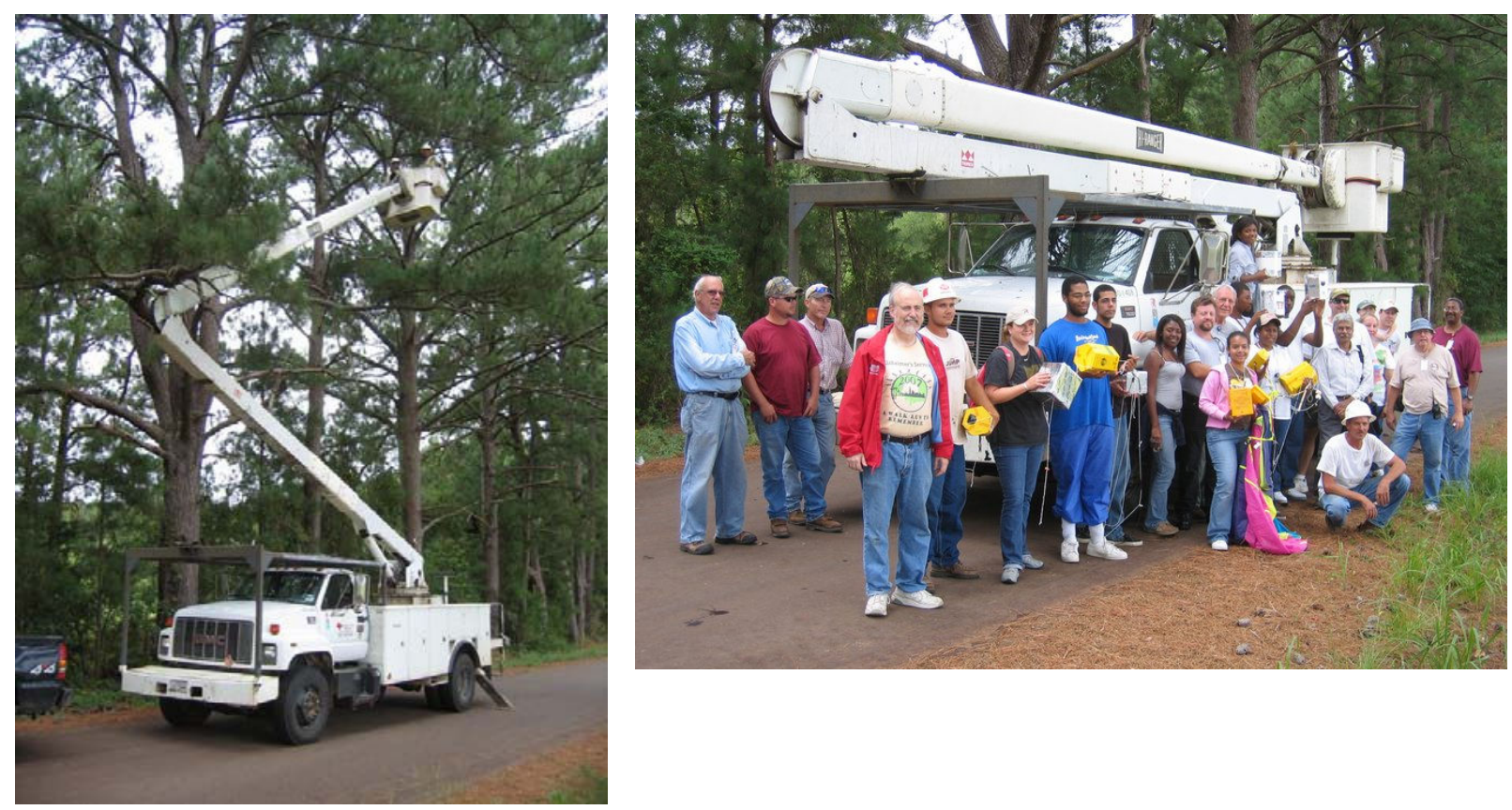

Figure 6. Collecting the payload from treetop. What a relief!

temperature (about $15^{\circ} \mathrm{C}$ cooler at higher altitude) from the temperature measured on the outside surface of the payload box due to internal heating of the electronics components as shown in Figure 8. The variation of surface temperature during ascent and descent was shown in Figure 9 indicating substantially lower temperature during descent at higher altitude because of faster rate of descent in the rarefied atmosphere. Also significant was the unexpectedly higher temperature

Flight Profile

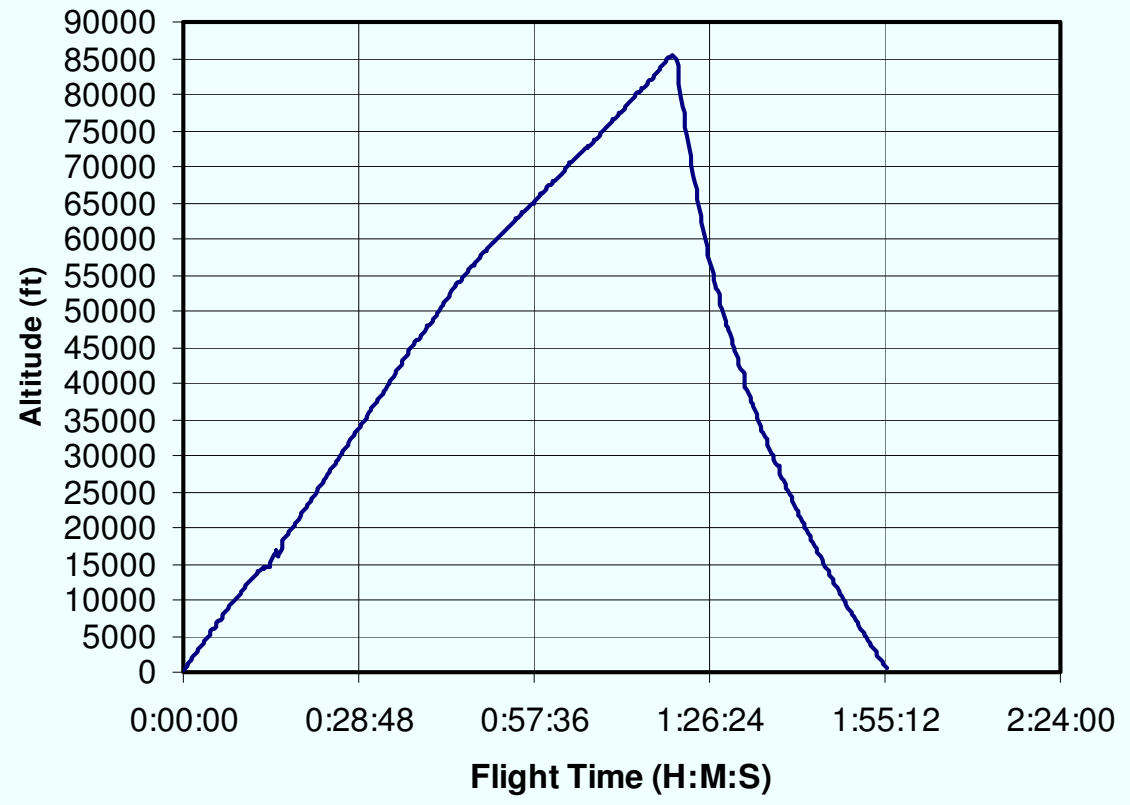

Figure 7. Balloon Flight Profile measured due to stormy condition existing at Palestine than measured by the weather balloon launched from nearby Fort Worth weather station as shown in Figure 10. ASU team's video camera did not record any images possibly due to moisture seeping into the camera compartment though the other team's still camera returned stunning images of the curvature of the blue earth against the darkness of space all the 
Comparison of Surface vs. Ambient Temperatures

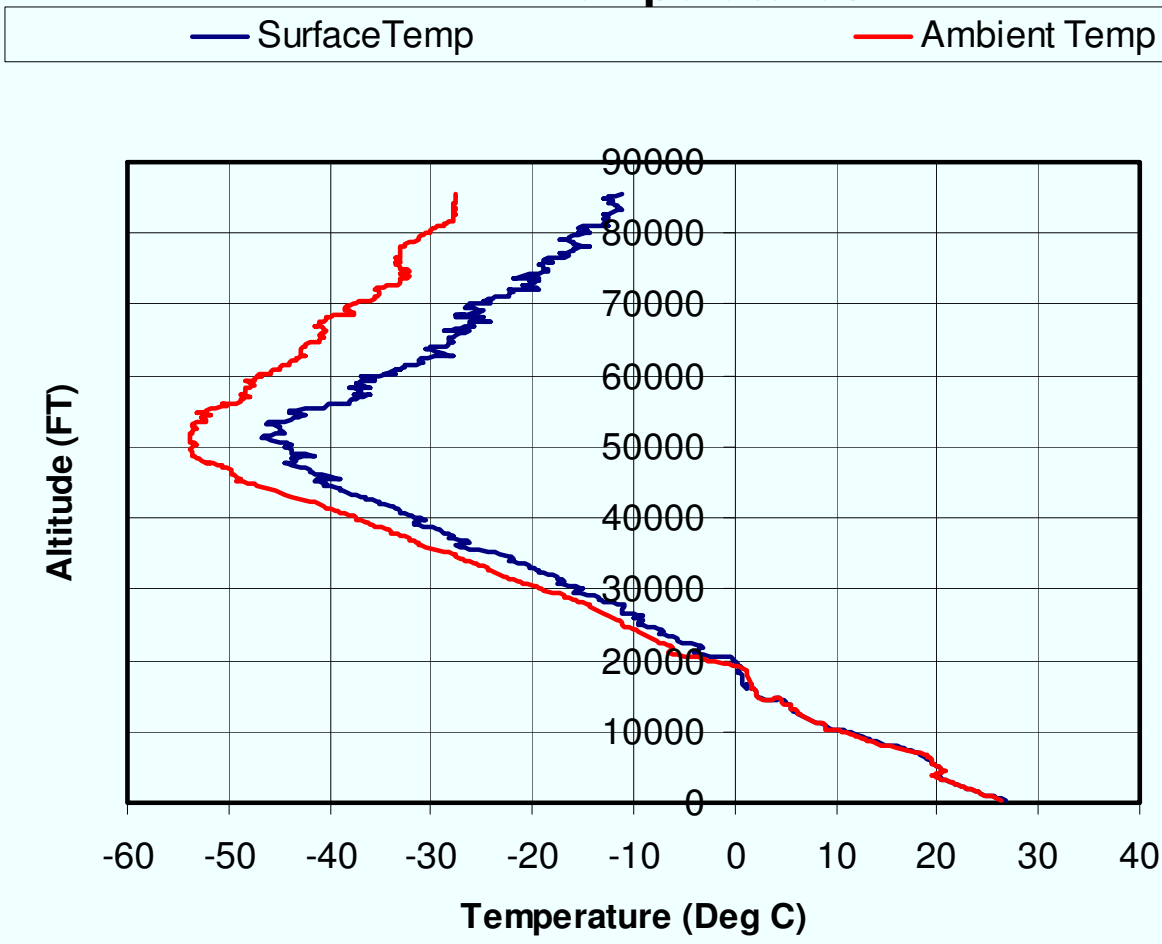

Figure 8. Comparison of ambient vs. outside surface temperature of the payload

Comparison of Temperature (Ascent vs. Descent)

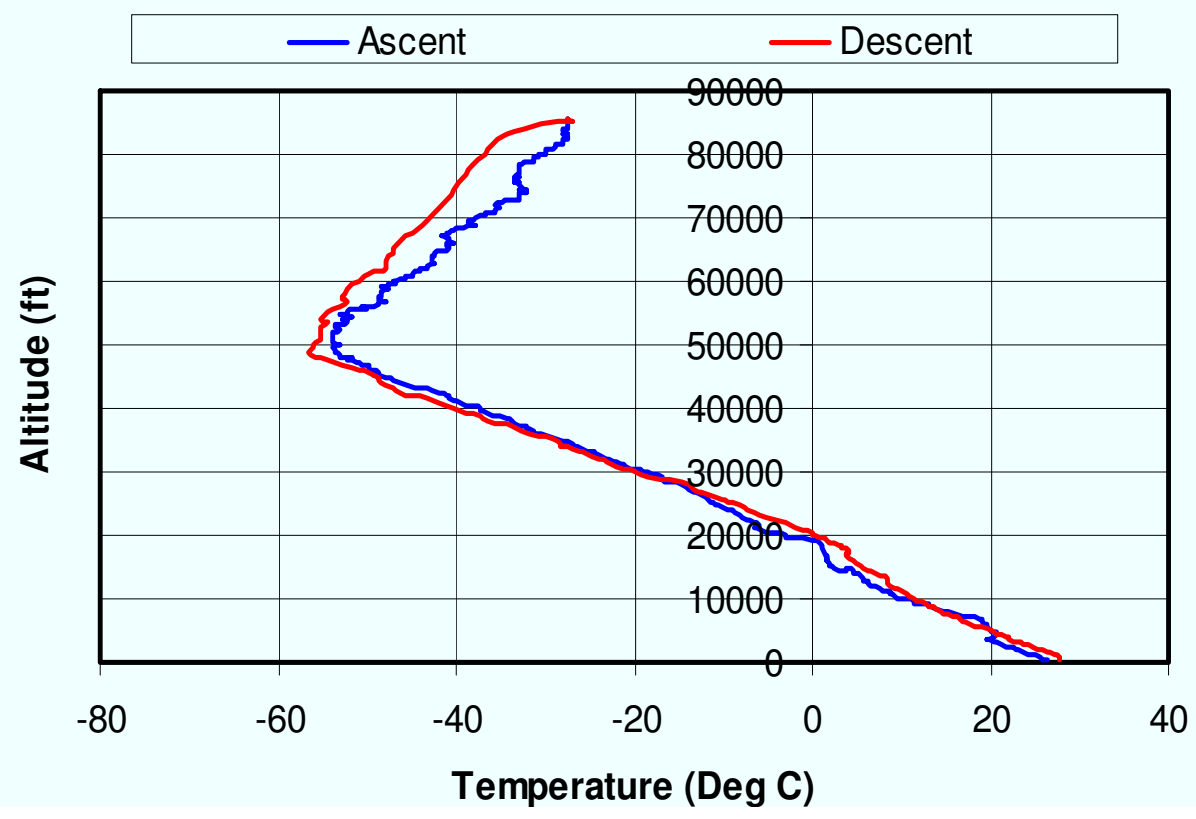

Figure 9. Surface temperature recorded during balloon's ascent and descent 
way to the point of balloon separation and return to ground. After the science presentation before the NASA personnel and PACER program officials was over, the teams returned to LSU next day. Following day the program ended with everyone leaving for home.

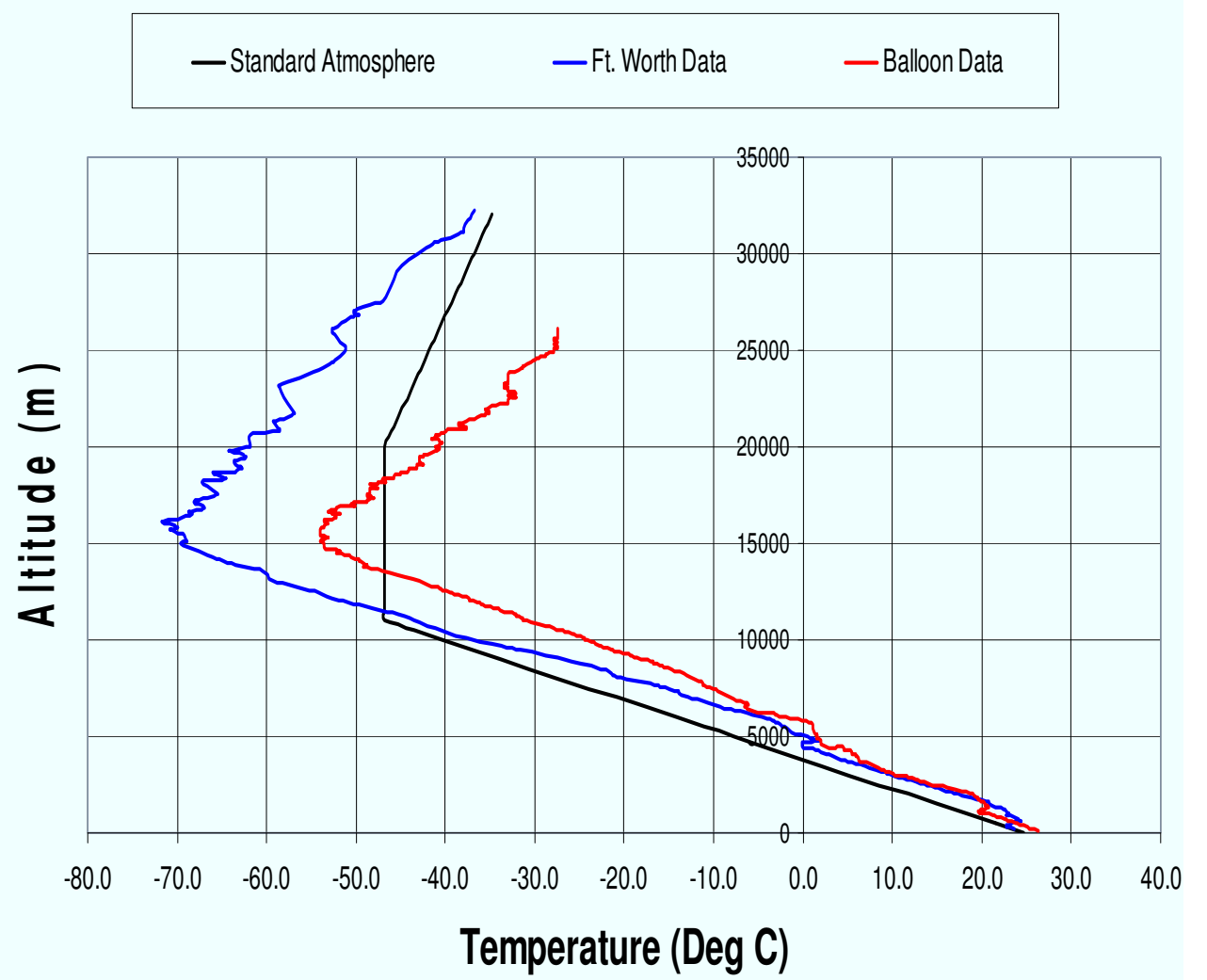

Figure 10. Temperature data collected from balloon and nearby Ft. Worth. The marked difference is believed to be the result of inclement weather at the launch site.

\section{Current Activities}

At the start of the 2009-10 academic year, a concerted effort was undertaken to recruit students for the ballooning project at ASU. Past summer's exciting activity at LSU and Palestine was reported to the faculty and student bodies by small group discussion and departmental seminar attended by over 70 people. However at the end only 3 students actually signed up for the project in spite of offering stipends available from various sources. The student ballooning course started in early September and met twice a week for 5 to 6 hours each week. As was done in LSU, we followed the same curriculum with the supporting hands-on activities. After the initial practice in soldering electronic components, the students developed SkeeterSat and program it to operate the LED's with temperature and light sensor input. They also completed the BalloonSat prototype board with all its peripherals. Just before the final exam of fall semester they have submitted prePDR report for review by the faculty advisors.

This year students started developing two different payloads. One of them will carry the BalloonSat with its array of pressure and temperature sensors and a digital camera as done 
previously with the exception of one additional temperature sensor to measure the inside temperature of the payload box to determine the temperature gradient from inside to outside. This will allow us to have a specific value of low temperature limit to decide on the operating range of the electronic components for future missions. As a new science experiment, the second payload is planned to have a microcontroller known as Arduino, an open source electronic prototyping platform that can receive input from a variety of sensors and can affect its surroundings by controlling lights, motors and actuators. A GPS module with data logging capability is planned to be attached to the Arduino microcontroller and GPS data logged to a SD flash memory card to be retrieved later for plotting on a Google map to display the balloon's actual flight path. Also, an array of solar cells attached to the outside surfaces of this payload box will measure the amount and change in energy collected as the balloon ascends through the atmosphere to determine if it can be used as a primary power source in future missions.

In the meantime, we have been able to contact a similar ballooning group operating from Columbus, GA. The team leader of that group was one of the original participants in the NASA Space Grant conference in 2002 and used to lead the ballooning project at Auburn University before moving to nearby Columbus. As a result there exists remarkable similarity of design and operation with LSU group, though they follow somewhat different mechanical construction procedure, electronic packaging and software for programming. Currently we are in the process of acquiring electronic components so that students can start fabricating the new sensor board which will be integrated with the BalloonSat for further testing of the circuit and software. We expect to launch our payload along with next balloon launch by the Columbus group which has been tentatively fixed at the first or second weekend of April 2010. Because of the time constraint, it was decided to postpone the launch of the second payload with Arduino, GPS module and solar cells for a future mission. Since the launch will take place within an hour's drive from the university, it will allow us to involve a larger group of students in the launch and recovery process, undoubtedly the most exciting part of the entire project.

\section{Ballooning Project: Sustainable Research Initiative}

The original intent of the PACER program is to create a sustainable student led research environment in a group of minority institutions which will act as a catalyst for extending the research activity in future. As expected in the beginning of any project one has to overcome many hurdles probably the most challenging one is to recruit a substantial number of dedicated students who will act as critical mass to carry the student ballooning project forward. Undoubtedly, our ballooning project has not reached that stage in the first year of operation though it is somewhat better off than most other participating institutions' projects in this year as is evident from the bi-weekly teleconference conducted by PACER program staff of LSU. But with the next successful launch and recovery, it is hoped that we will be able to change many minds from mere curiosity to active participation.

One positive aspect of our ballooning project is that we are relatively well off in terms of funding primarily because of ASU's status of affiliate membership in Georgia Space Grant Consortium. A portion of the annual funds allocated from Space Grant may be tapped into when support from NSF runs out at the end of three years. Also, the university has supported to the extent of $\$ 4000$ made available from the indirect funds account from various federal grants awarded which is 
being used to pay stipends to the students. University also has approved one course release time past fall semester for the principal investigator which demonstrates their commitment to support student research in science and engineering.

\section{Challenges Faced and Future Plans}

The primary problem as already mentioned is recruitment of enough students to make this a viable project. A non credit Student Ballooning Course may appear to be a non starter even with sufficient financial incentive. It may also pose continuous challenge to have the students attend classes or hands-on activities specifically before a long weekend or prior to any upcoming test. Though awarding stipends does provide some incentive, it by no means ensures complete student engagement. To address this problem, after much discussion with the chair of Mathematics and Computer Science department, it was agreed upon to offer SBC as an elective course called CSCI 4911 - Special Topics "Real Time Programming" in the upcoming fall semester. Students majoring in Computer Science will get credit for this 3 credit hour course which will fulfill the requirement of one of the elective courses for that major program. Also, students enrolling in this course will be juniors and seniors who are expected to be more engaged in the subject matter rather than the current students who are mostly freshmen. The students who complete this course successfully will be invited to join the payload design and fabrication project in the ensuing spring semester for which they will be paid stipend. This proactive "recruitment" approach will hopefully resolve the continuing challenge of low enrollment and limited engagement in the project in the coming academic year.

In the end after experiencing first hand the excitement and sheer joy of participating in a balloon launch it can safely be said that the best way of ensuring the project's success is to get maximum number of students participate in the launch day activities. We can indeed be able to do so as our next launch site will be no more than an hour's drive from the home institution. Students who have seen a balloon launch will have a dramatically changed attitude towards ballooning as a research tool and will be our best recruiting agent for the project in future.

\section{Bibliography}

1. Liefer, R.K., "Into Space Without a Rocket (and Not Much Money, Either)", Proceedings of the 1996 ASEE Annual Conference and Exposition.

2. Wick, C., et al, "Sensors for a Weather Balloon - a Classroom Design Experience", Proceedings of the 1996 ASEE Annual Conference and Exposition.

3. Won, C., et al, "Spacecraft Systems Engineering - The Initiation of a Multidisciplinary Design Project at the University of North Dakota", Proceedings of the 2001 ASEE Annual Conference and Exposition.

4. Ellison, B., et al, "The Louisiana ACES student-built BalloonSat program", ScienceDirect, Advances in Space Research, Elsevier, 2006.

5. http://casgc.ucsd.edu/?=396, California Space Grant Consortium, retrieved on January 1, 2010. 